\title{
Qué hacer cuando arde la red: gestión de crisis de comunicación on-line
}

AUTORES / AUTHORS

José Manuel Burgueño

10 de noviembre de 2020

- Páginas / Pages

De la 381 a la 383

EDITORIAL / PUBLISHING COMPANY

- ISSN: 1885-365X

Barcelona, Editorial UOC, 2018, 250 pp.

https://www.editorialuoc.com/que-hacer-cuando-arde-la-red

La Web 2.0 - primera gran revolución para la que se acuñó la denominación de Web socialsupuso un cambio disruptivo en numerosos ámbitos. Uno de ellos fue la relación que las empresas tenían respecto a los clientes, ya que pasaba a ser más directo y estrecho en virtud de diversos canales. Entre ellos podemos citar, sin ánimo agotador, los sitios Web oficiales e institucionales presentes en la Red, así como los blogs y las redes sociales. Todos son paradigmas que ponen de manifiesto la concurrencia de una comunicación bidireccional en la que el público cobra un protagonismo muy significativo. Cuando hacemos alusión a público en la Red nos referimos tanto a clientes - que tienen cierto vínculo con marcas y/o productos - como a usuarios en general -la población. Con la Web 3.0 o Web semántica, que es en la que actualmente nos encontramos (sin perjuicio de que ya se habla del 4.0), se da un paso más allá.

La preocupación por la comunicación de las crisis ocupa una posición de cierta actualidad después de que las organizaciones tomen conciencia de cuanto y de qué forma puede afectarles una crisis que no se ha gestionado de manera oportuna. Existen actuaciones que pueden provocar un rechazo manifiesto de los potenciales clientes o de la opinión pública en general. Hay comportamientos que, en toda esta problemática, deben evitarse como guardar silencio, respuestas tardías y estrategias no coordinadas. A fecha de hoy, ninguna empresa u organización puede evitar poner en marcha un plan de acción que se siga en el supuesto de que se desate una crisis. En realidad, como apuntó, en 1982, el presidente y también fundador de Burson Masteller Corp., Harold Burson, cuando nos refiramos a las crisis, «sólo conozco dos tipos de empresas u organizaciones: las que han sufrido una crisis y las que la sufrirán».

A todo ello se refiere la sugerente obra de José Manuel Burgueño. Respecto a su formación, es Doctor en Ciencias de la Información. Asimismo, es periodista, comunicador y profesor universitario. Cabe reseñar que, durante más de una década, prestó servicios en importantes medios de comunicación españoles de primer nivel. Ha sido merecedor de distintos premios entre los que puede citarse el de Periodismo de Telecomunicaciones Vodafone o el Periodismo Económico Diageo. Igualmente, ha sido Director de Comunicación de importantes empresas. Finalmente, poner de relieve que es autor de numerosas obras en el ámbito del periodismo. 
Por lo que respecta a la sistemática de la obra, procede apuntar que se estructura en cinco grandes capítulos que seguidamente esbozaremos de forma somera.

El primero de ellos alude al concepto de reputación. En su contenido se analizan las diferencias y similitudes entre imagen y reputación online. Posteriormente, se centra en el paradigma en esta materia: las redes sociales. Como acertadamente dijo Warren Buffett a su hijo «cuesta veinte años construir una reputación y bastan cinco minutos para arruinarla». No cabe duda de que, como la propia realidad cotidiana atestigua, una crisis puede destrozar una trayectoria impecable de años. Con la Red probablemente esta máxima se reduce a segundos. El posicionamiento en buscadores y la viralidad que se suscita en las redes sociales representan dos elementos clave que conlleva que sea muy relevante lo que se dice en la Red de nuestra organización o nuestra marca. Sabiendo lo que realmente se dice en Internet podremos llegar a diseñar una estrategia de comunicación online para potenciar las opiniones favorables, trabajar en las negativas y reaccionar a tiempo en supuestos de crisis.

Las crisis que pueden llegar a suscitarse en las redes sociales son objeto de atención en el capítulo siguiente. La mejor estrategia de comunicación para que la imagen de una organización salga reforzada de una crisis es la que se implanta con rapidez, pero sin precipitarse. Debe procederse con transparencia y de manera honesta, pero con precaución. Con la Web 2.0 el entorno ha cambiado, de manera abrupta, dado que pasa a funcionar con nuevas reglas. En cualquier caso, la inmensa mayoría de los principios elementales para gestionar adecuadamente esta crisis permanecen. Si bien en las redes sociales pueden suscitarse situaciones que, por las circunstancias concurrentes, pueden ser ciertamente complejas, no siempre pueden considerarse una crisis reputacional de índole digital. Especialmente sugerente resulta la descripción de la crisis que se sufrió por parte de Volkswagen -a propósito del dieselgate-. Manipuló mediante programa informático las emisiones de sus motores diesel para que, al efectuar el test de emisiones, se redujeran de manera automática, con el único fin de cumplir la normativa. Su funcionamiento normal era cuarenta veces superior al estándar según las investigaciones desarrolladas por la Agencia de Protección Ambiental de los Estados Unidos. El fraude afectaba a más de once millones de vehículos de todo el mundo. El presidente de la compañía dimitió, su valor bursátil se desplomó, la venta de acciones se disparó y las posibilidades de quiebra de la compañía se incrementaron. Las crisis, en general, se pueden definir por la sorpresa, la amenaza, la desestabilización, la urgencia, la tensión, el estrés, la pérdida de control y el desafío. Todas estas características se trasladan a los estados de ánimo de sus protagonistas.

La comunicación de crisis en la Red se examina en el capítulo tercero. Uno de los grandes errores que padecen las organizaciones es pensar que la crisis no les afectará. De manera cotidiana, las organizaciones tienen que hacer frente a situaciones críticas. En el mundo virtual, las acciones más habituales que llevan a una crisis son de tres tipos:

- comentarios negativos que no se gestionan adecuadamente y que se descontrolan;

- errores cometidos por parte de la propia organización en la Red -comentarios fuera de lugar, juicios de valor, mala estrategia de marketing;

- quejas de trabajadores o ex empleados.

Tiene que existir un plan de crisis en el que se detalle la manera en la que se actuará en el supuesto de que se llegue a una situación de crisis porque no se puede dejar a la improvisación. 
El capítulo cuarto alude a cincuenta supuestos reales de crisis online que se han suscitado en organizaciones o empresas con la manera -con sus aciertos y errores - en la que se han gestionado. Existen ejemplos de todos los sectores y países (textil, automoción, comida, viajes y un largo etcétera). Entre todos los supuestos que el autor enuncia, podríamos, a título de ejemplo, referirnos al caso de la aerolínea norteamericana United (ruta de Chicago a Louisville en Estados Unidos). En 2017 vendió más billetes de avión que asientos tenía el vuelo (overbooking). Según señaló por megafonía necesitaba cuatro asientos para que la tripulación los usase. A cambio daba una compensación económica inicial, una noche de hotel y un billete de avión al día siguiente. Dado que originariamente la oferta no se aceptó, se mejoró, pero tampoco logró su fin. La compañía procedió a la selección de los pasajeros que abandonarían el avión por sorteo. Aunque tres de ellos lo hicieron voluntariamente, el cuarto -un médico que al día siguiente debía trabajar - se negó a tal actuación. Sin embargo, lo sacaron a la fuerza generándole numerosas lesiones y, con ello, se desató una crisis de reputación de la compañía sin precedentes. Aunque, inicialmente trató de justificar la violencia empleada hacia el pasajero por su actitud, las grabaciones pusieron de relieve que no opuso ningún tipo de resistencia. Finalmente, para evitar una demanda judicial - probablemente millonaria - la empresa llegó a un acuerdo económico con el afectado cuya cuantía no trascendió.

El último capítulo se refiere a las conclusiones, pautas y recomendaciones que se derivan de la obra. Como el autor magistralmente expone a lo largo de la monografía, cada crisis resulta única. Resulta ciertamente infrecuente que dos crisis tengan las mismas causas y, dado el caso, las mismas causas jamás producirán los mismos efectos. Un paso fundamental para salir airoso de las crisis siempre será detectar el problema que lo ha generado, asumirlo y resolverlo. Deben, en suma, aplicarse estrategias o tácticas de comunicación para controlar los riesgos que son susceptibles de amenazar la reputación, el prestigio y la marca de una organización.

En definitiva, la obra que es objeto de reseña representa una magistral exposición de cómo proceder frente a las crisis de la comunicación online. Las pruebas y dificultades que la vida misma supone pueden hacernos caer en la melancolía y el pesimismo o bien puede hacernos más fuertes y mejores personas. Lo mismo acontece en las crisis corporativas. Como el contenido de la monografía señala, es posible salir reforzado con una mejor reputación si se gestiona correctamente y se sabe aprovechar la oportunidad. La lógica pone de manifiesto que el progreso requiere el aprendizaje desde el fracaso.

Por Dr. Patricia Vargas Portillo

ESIC Business \& Marketing School, España.

@ jennypatricia.vargas@esic.edu (iD) 0000-0002-0226-3053 